\title{
Weak bands within Ice Stream B, West Antarctica
}

\author{
C. L. Hulbe, ${ }^{*}$ I. M. Whillans \\ Byrd Polar Research Center and Department of Geological Sciences, The Ohio State University, Columbus, Ohio 43210, U.S.A.
}

\begin{abstract}
Kilometer-scale variations in ice velocity and surface topography are used to investigate the style of glacier deformation in the main body of Ice Stream B, West Antarctica. The pattern is very different from that reported for other glaciers. For the $250 \mathrm{~km}^{2}$ area studied on Ice Stream B, most of the observed deformation occurs within two narrow bands, in which there is large across-flow compression and slow lateral shearing. The bands underlie valleys in the ice-surface topography. Measured upward displacement of ice adjacent to the rapidly compressing bands appears to be linked to the creation of the ice stream's topography. The most likely cause for the observed pattern of strain rates and surface topography, and their changes over time, is deformation guided by longitudinal bands of ice with an aligned crystal fabric.
\end{abstract}

\section{INTRODUCTION}

It is usually supposed that the strength of ice varies in a simple way with position in a glacier. Ice strength decreases with depth and perhaps also close to the lateral margins of a glacier. This view allows large-scale modelling of ice flow using concepts of continuum mechanics (c.g. Paterson, 1981; Hutter, 1983). Many tests of these concepts have been made on glaciers and ice streams. Examples of such studies on temperate glaciers include a straight section of Athabasca Glacier, Alberta, Canada (Raymond, 1971) and over a riegel under Storglaciären, Sweden (Hooke and others, 1989). Tests have been made on polar glaciers at Dye-3 in southern Greenland (Van der Veen and Whillans, 1990); along the Byrd Station strain network in the interior of the West Antarctic ice sheet (WAIS; Whillans and Johnsen, 1983); and on Barnes Ice Cap, Canada (Hooke and Hanson, 1986). A new test, by Whillans and Van der Veen (1993b) on Ice Stream B, West Antarctica (Fig. 1), produced unexpected results that called into question some assumptions about spatial variations in ice strength and flow, especially that these variations are primarily in the vertical direction.

Patterns in surface strain rate and surface slope on Ice Stream B are unusual (Hulbe and Whillans, 1994). The patterns do not appear to be caused by flow over or around basal topographic features or sticky spots. Force-budget analysis of the surface strain rates produces negative basal drag in some areas, which is physically improbable (Whillans and Van der Veen, 1993b). Furthermore, topographic features are not advecting downstream at the speed of surrounding ice, as would be expected if they were similar to rafts identified elsewhere in West Antarctica Bindschadler and others, 1987). Instead, the surface topographic features are slowly migrating up- and across-glacier. None of the usual explanations for horizontal variations in strain rate seem appropriate for the Ice Stream B data.

\footnotetext{
* Present address: Department of Geophysical Sciences, University of Chicago, 5734 S. Ellis Avenue, Illinois 60637, U.S.A.
}

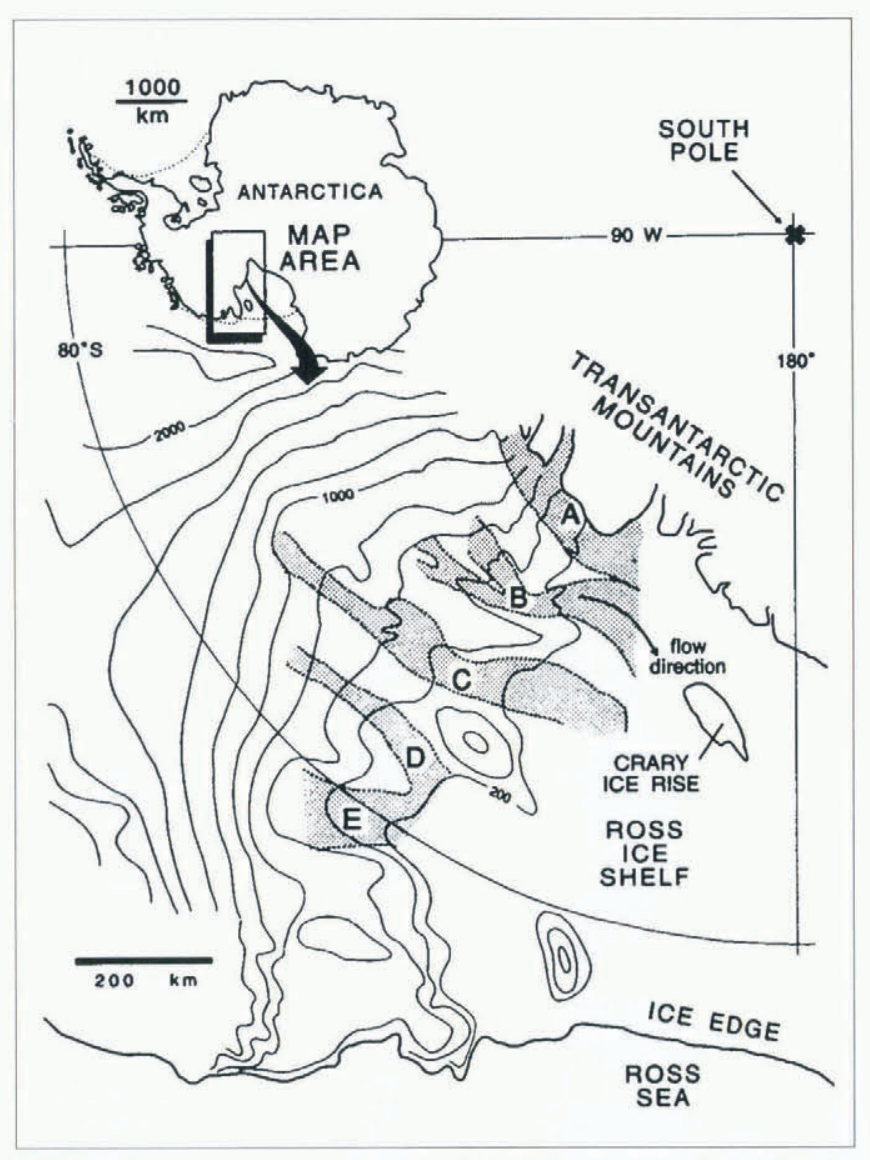

Fig. I. Map of West Antarctica. Ice streams are shaded and labeled, A-E. The study is conducted near the "UpB camp" on Ice Stream B. Surface contour interval is $200 \mathrm{~m}$.

Here, precision Global Positioning System (GPS) measurements of an extensive strain grid near the $\mathrm{UpB}$ camp are used to address more thoroughly the nature of unusual flow patterns first identified by Whillans and Van der Veen (1993b). The work is more thorough because the new grid is much larger and because relative vertical velocities are obtained in addition to horizontal velocities. The earlier 
strain grid of Whillans and Van der Veen (1993b) is incorporated into the present grid, allowing time-changes in strain rate and topography to be observed.

Some analyses of the present data are given in Hulbe and Whillans (1994). That report describes the GPS-survey method and presents the strain rates and vertical velocities. It seeks, but fails, to explain the measured strain-rate gradient and surface slope patterns in terms of sticky spots (sites of extra basal friction or partial blockage of flow). Here those results are re-evaluated and new comparisons are made with older strain-rate and surface topographic observations. A more straightforward model is proposed. It involves horizontal variation in ice strength, and accounts for more of the observations than did Hulbe and Whillans (1994).

\section{FLOW CHARACTERISTICS}

Velocity gradients and surface topography from surveys conducted in late 1984 and late 1985 (used by Whillans and Van der Veen (1993b), referred to as 1984-85), and late 1991 and late 1992 (1991-92) are used to analyze ice flow. Surveying methods and errors are discussed in Appendix 1. Topographies for the large strain grid measured in 1991 and for the smaller grid measured in 1984 are shown in Figure 2. Gridpoint velocities and positions are tabulated in Hulbe (1994). Plots of the velocity gradients for the entire strain grid are in Hulbe and Whillans (1994). Here attention is directed toward the two sites of most extreme velocity variation, shown in Figures 3 and 4.

Local reference frames are defined such that comparisons are made with respect to the same portion of the bed. The $x$ axis of the coordinate system used to plot the data lies along the long axis of the grid and is positive down-glacier. The $y$ axis is perpendicular to the $x$ axis and is positive toward the southern (glacier-left) shear margin. Velocity gradients are calculated in a coordinate system $(l, t)$ that is more significant to glacier flow. The longitudinal $(l)$ axis is rotated to be parallel to ice flow, $10^{\circ}$ clockwise from the $x$ axis. The transverse $(t)$ axis is perpendicular to the $l$ axis and is rotated $10^{\circ}$ clockwise from the $y$ axis. Both coordinate systems are fixed and do not translate or rotate with ice motion.

\section{Topography of the snow surface}

There is considerable surface relief within the study area. Peak-to-trough vertical distances are about $30 \mathrm{~m}$ over $10 \mathrm{~km}$. Three features are of particular interest. They are an up-glacier hill, at $(x, y) \approx(-11,-7)$ to $(-15,-8) \mathrm{km}$; a neighboring up-glacier valley at $(x, y) \approx(-15,-6) \mathrm{km}$ (in Figs 2 (top panel) and 3a); and a down-glacier valley, at $(x, y) \approx(-1,-9.5) \mathrm{km}$ (in Figs 2 (top panel) and $4 \mathrm{a})$. None of the three features have corresponding basal relief (Retzlaff and others, 1993; Novick and others, 1994).

\section{Changes in topography over time}

Both the up-glacier hill and down-glacier valley have moved during the 7 year interval between survey pairs (cf. upper and lower panels, Fig. 2). The up-glacier hill has moved at least $1 \mathrm{~km}$ glacier-leftward and $2 \mathrm{~km}$ down-glacier. The axis of the down-glacier valley has migrated up-glacier and/or to the glacier-left about $1.5 \mathrm{~km}$ (it is not possible to discern the precise direction of migration, because the feature is linear and diagonal to the direction of ice flow). The two features are now closer together. The glacier-right flanks of the downstream valley and the valley to the glacier-right of the upstream hill must both have moved vertically upward to achieve the observed changes in topography.

Evolution of the topography may also be evaluated using measured vertical velocity of the ice-stream surface. The relative vertical motions of grid poles are available for the 1991-92 interval. A vertical velocity anomaly is defined as the difference between observed vertical velocity and vertical velocity predicted for steady ice flow through surface features. It is calculated assuming zero vertical displacement for a site where the surface slope is very small (Figs $3 \mathrm{~b}$ and $4 \mathrm{~b}$ ). For most of the grid, the anomaly is near-zero, indicating that the features are fixed with respect to the bed (stationary waves in ice flow). However, extra motion is as-

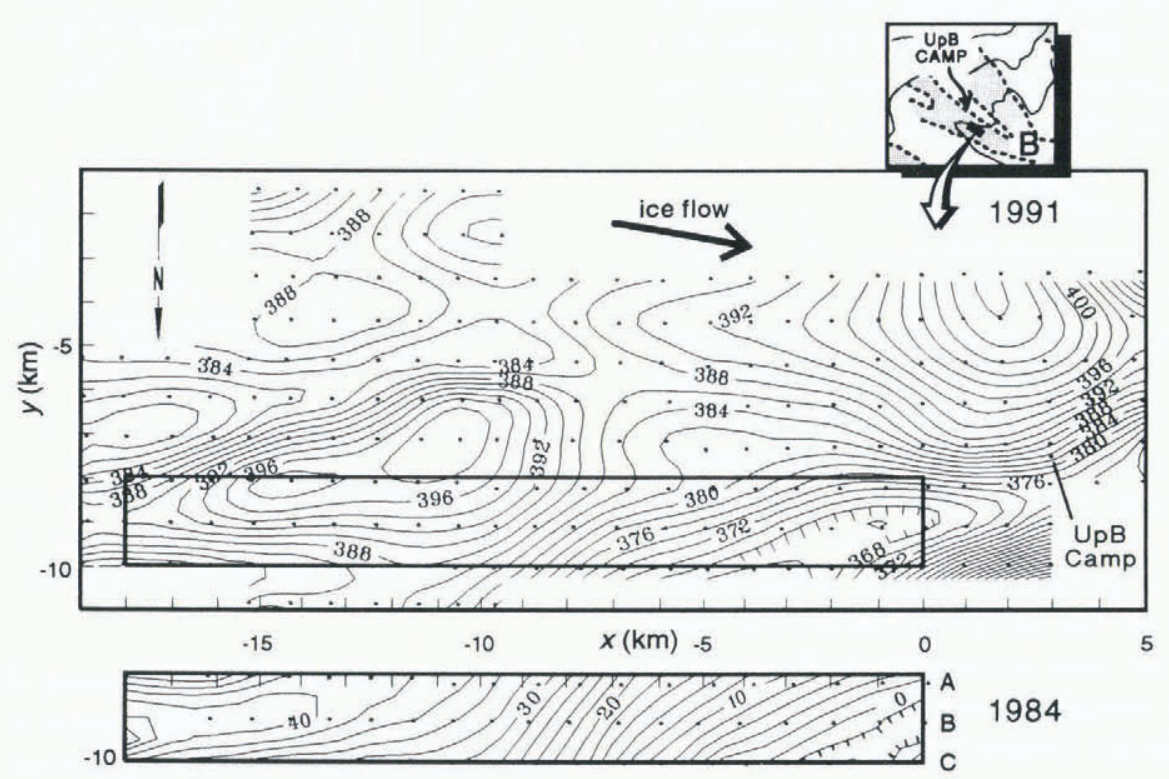

Fig. 2. Ice surface topography in 1991 and 1984, with respect to the same portion of the bed. Dots indicate the positions of survey markers in the strain grid. Contour interval is $2 \mathrm{~m}$. Contours in the 1984 map are difference in height from the " 0 " meter contour. Contours in the 19.91 map are height of the snow surface above the ellipsoid (WGS84). The " $A$ ", " $B$ ", and " $C$ " lines are along $y \approx$ $-8,-9$ and $-10 \mathrm{~km}$, respectively. 

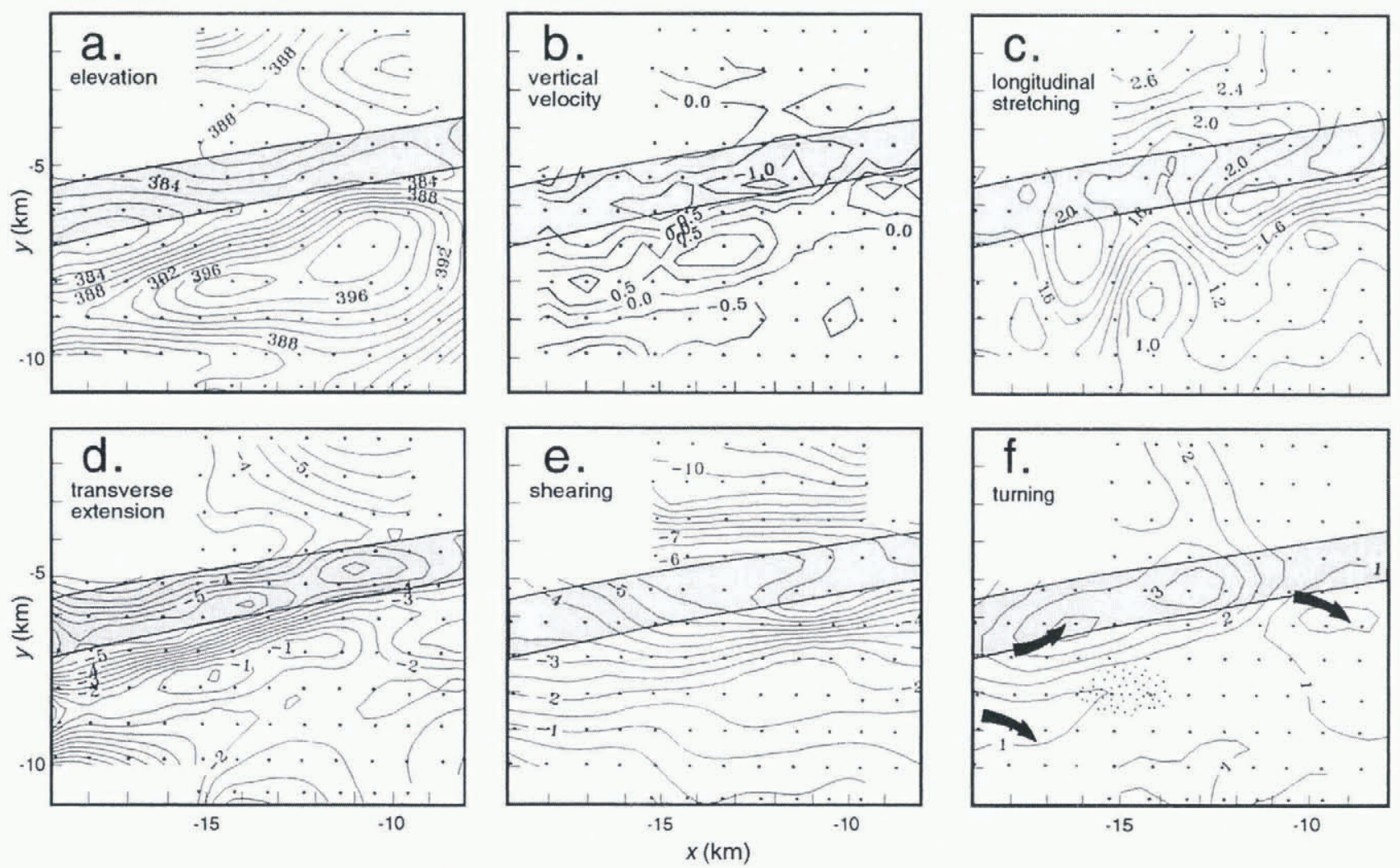

Fig. 3. Surface topography and velocity patterns in the up-glacier hill and valley area. A hypothetical aligned-crystal ice band is shaded in each panel. (a) 1991 surface topography, as in Figure 2. (b) Vertical velocity anomaly, the difference between observed vertical component of velocity and the product of ice speed and local surface slope. Isotach interval is $0.5 \mathrm{~m} \mathrm{a}^{-1}$. Positive velocities are upreard. (c) Longitudinal stretching $\left(\partial u_{l} / \partial l\right)$. Isoline interval in all velocity gradient maps is $0.5 \times 10^{3} a^{\prime}$. (d) Transverse extension $\left(\partial u_{t} / \partial t\right)$. (e) Lateral shearing $\left(\partial u_{l} / \partial t\right)$. $(f)$ Flowline turning $\left(\partial u_{t} / \partial l\right)$. Variations in turning with respect to the regional leftward turning of $2 \times 10^{3} a^{-I}$ are indicated by arrows. Stippling indicates sites that the flow tends to "avoid".
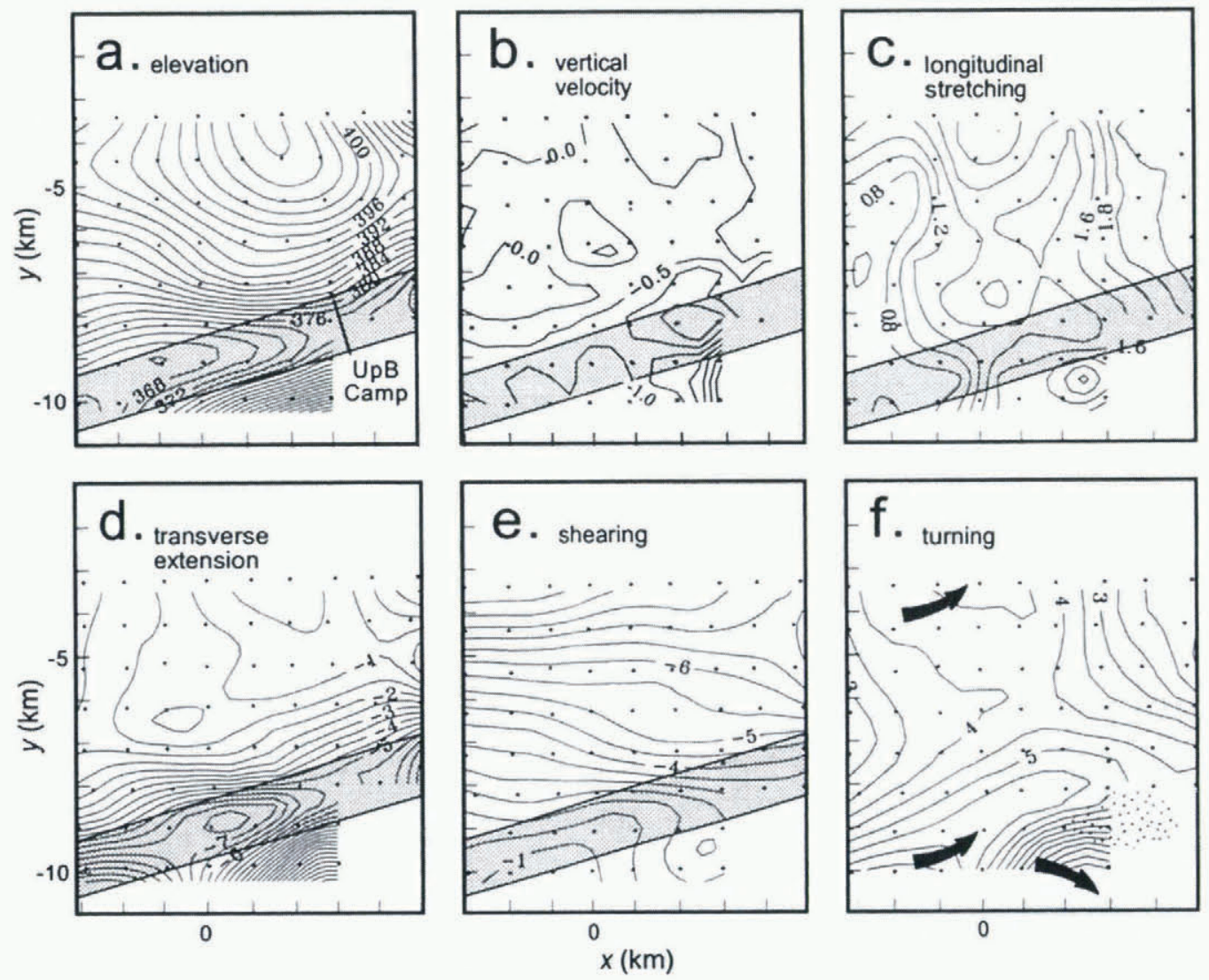

Fig. 4. Topography and velocity patterns in the down-glacier valley area. Panel descriptions are the same as in Figure 3. 
sociated with the migrating topographic features. The glacier-right flank of the up-glacier valley is being displaced upward, by as much as $1 \mathrm{ma}^{-1}$. In contrast, its glacier-left flank is moving relatively downward, as much as $1 \mathrm{ma}^{-1}$. The down-glacier valley also has an anomalous negative vertical velocity on its glacier-left flank and floor. The simplest interpretation is that ice on the glacier-left sides of the valleys is moving relatively downward while ice on the glacier-right is moving relatively upward.

The changes observed over the 7 year (topographic comparison) and 1 year (vertical velocity anomaly) intervals are consistent. Ice on the glacier-right sides of both valleys is moving upward over time for both time-spans. This contrasts with the expected pattern due to the advection of ice rafts, which have been observed elsewhere in the WAIS (Bindschadler and others, 1987; Whillans and others, 1987, 1993). Rafts advect at the speed of surrounding ice. The topography near $\mathrm{UpB}_{\mathrm{p}}$ is either stationary or moving contrary to ice flow.

\section{Velocity}

The direction and magnitude of ice motion changed between the 1984-85 and 1991-92 surveys. The 1991-92 along-grid $(x)$ and across-grid $(y)$ components of velocity are about 420 and $-47 \mathrm{ma}^{-1}$ at the up-glacier end of the grid, and about 430 and $-16 \mathrm{~m} \mathrm{a}^{-1}$ at the down-glacier end. Along-grid velocity has decreased since 1984-85, by about $15 \mathrm{~m} \mathrm{a}^{-1}$ at the down-glacier end of the grid and somewhat less, about $8 \mathrm{ma}^{-1}$, up-glacier. Across-grid velocity has become less negative (slower flow toward the center of the ice stream), by as much as $20 \mathrm{~m} \mathrm{a}^{-1}$, at the down-glacier end of the grid, but the difference is nearly zero up-glacier. The combined result is that ice motion is more to the glacier-left in the down-glacier end of the grid and has slowed by about $5 \%$ (velocity error $<1 \%$ ), while at the upglacier end there is a decrease in speed but no change in direction.

\section{Longitudinal stretching $\left(\partial u_{l} / \partial l\right)$}

Longitudinal (along-flow) normal strain rates are extensive. There are large variations on the several kilometer scale (Figs 3c and 4c). The variations do not correspond to changes in surface slope, as would have been expected were they due to flow over a basal obstruction (Whillans and Johnsen, 1983). Time-changes in longitudinal stretching are shown in Figure 5.

The grid-wide pattern of relatively more and relatively less extension has remained fairly constant over time (Fig. 5). Magnitudes have decreased by about $20 \%$. An exception is found along the glacier-right flank of the up-glacier hill (A-B lines $\sim-13.5 \mathrm{~km} ; \mathrm{B}-\mathrm{C}$ lines $\sim-13.5$ to $-15.5 \mathrm{~km})$. The overall decrease in stretching is due to the larger decrease in along-grid velocity occurring at the down-glacier end of the grid.

\section{Transverse compression $\left(\partial u_{t} / \partial t\right)$}

Transverse (across-flow) normal strain rates are negative due to across-flow compression as the ice stream narrows (Vornberger and Whillans, 1990). Superimposed on this are local variations, most notably the large compression concentrated in narrow bands at the sites of the surface valleys (Figs $3 \mathrm{~d}$ and 4d). A simple topographic relaxation model
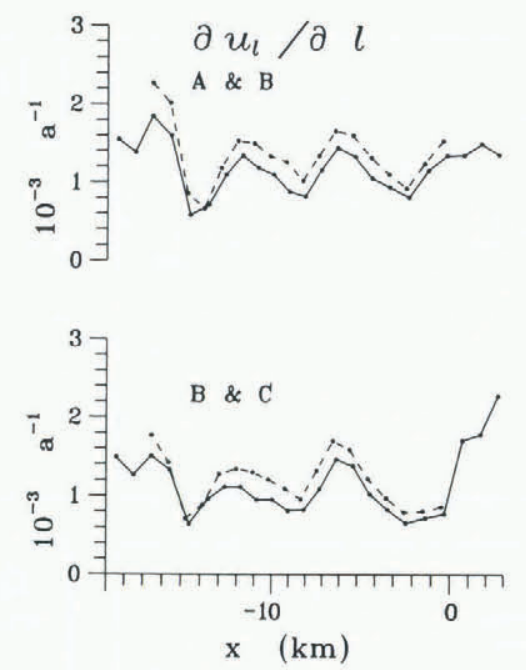

Fig. 5. Profiles of longitudinal stretching, $\partial u_{l} / \partial l$, in $10^{3} a^{-l}$, along transects between the $A$ and $B$, and $B$ and C lines. Gradients are calculated at the centers of quadrilaterals formed using four adjacent grid points, and are plotted at the $x$ direction midpoints of the quadrilaterals. Dashed and solid lines represent the 198485 and 1991-92 observations, respectively. The $x$ axis (in this and Figs 4 and 6) corresponds to the $x$ axis on the topographic maps (Fig. 2). There is an overall decrease in stretching of about $20 \%$. This is due to the larger decrease in along-grid velocity occurring at the down-glacier end of the grid. The pattern of relatively more and relatively less stretching has remained fairly constant. An exception, at $\approx-14 \mathrm{~km}$, is on the glacier-right flank of the up-glacier hill.

suggests that the topographic variation does not account for the local variations in compression (Hulbe and Whillans, 1994). That model sought, but failed, to reproduce the surface topography from observed strain rates using both linear and non-linear relationships between topography and transverse compression and a range of ice viscosities. Strain rates in the valleys are too compressive to be caused by surface relaxation alone.

Time-changes in topography and in transverse compression are correlated. In the down-glacier end of the grid, the location of maximum compression (most negative $\partial u_{t} / \partial t$ ) has moved up-glacier (Fig. 6, B C lines, from $\sim-0.5$ to $-1.5 \mathrm{~km}$ ). This is the same as the movement of the downglacier valley (Fig. 2). Only the glacier-rightward edge of the upstream band of rapid compression is measured in both the 1984-85 and 1991-92 studies. Here too, migration of topography and sites of rapid transverse compression appear to be connected. The up-glacier hill moved to the glacier-left between surveys, and compression increased leftward (ahead) of it (Fig. 6, A-B lines $\sim-14$ through $-16.5 \mathrm{~km}$ ) and decreased rightward of it (in its wake) (Fig. $6, \mathrm{~A}-\mathrm{B}$ lines $\sim-10$ through $-14 \mathrm{~km}$; B $-\mathrm{C}$ lines $\sim-9$ through $-16.5 \mathrm{~km})$. In both the down-glacier and up-glacier cases, the correlation between surface valleys and extreme compression is preserved as the valleys migrate.

\section{Lateral shearing $\left(\partial u_{l} / \partial t\right)$}

Lateral shearing, the across-stream gradient of along-flow velocity, is largest (most negative) near the margin, and approaches zero at the kinematic center line of the ice stream. The gradient of the shear strain rate is not simple, as would be expected if ice strength and basal resistance 

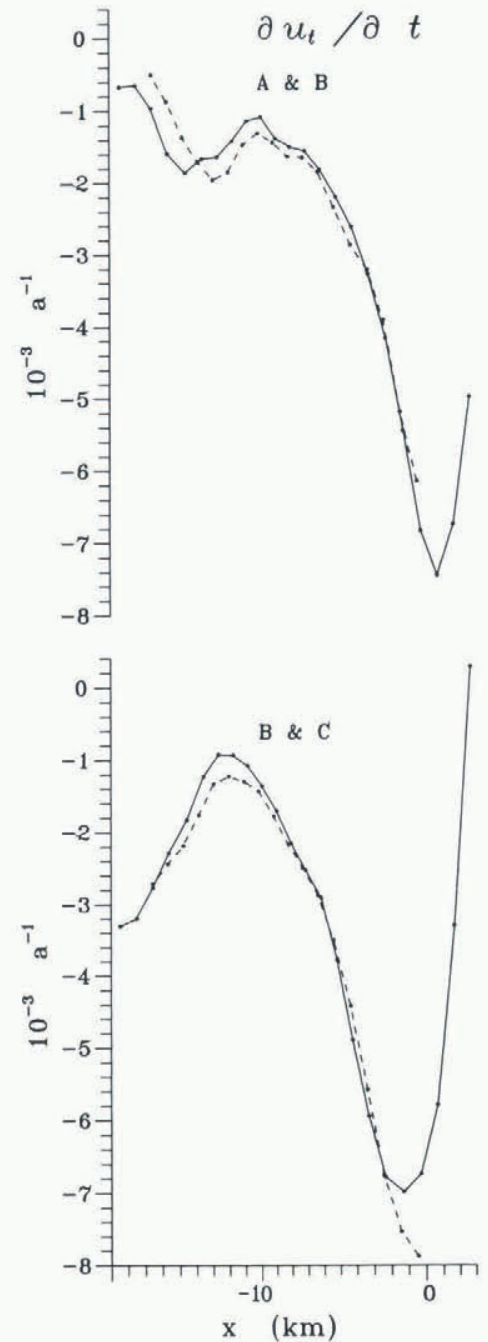

Fig. 6. Profiles of transverse compression, $\partial u_{t} / \partial t$, in $10^{-3} a^{-1}$. Local compression maxima have migrated in the same sense as surface topographic features (see Fig. 2).

were spatially homogeneous. Instead, there are several zones where the spatial gradient in shearing is very small: from $(x, y) \approx(-16,-6) \mathrm{km}$ to $(x, y) \approx(-10,-5) \mathrm{km}$ in Figure $3 \mathrm{e}$, and from $(x, y) \approx(-2,-10) \mathrm{km}$ to $(x, y) \approx(2,-8) \mathrm{km}$ in Figure 4e. A possible interpretation is that ice within these narrow (about $2 \mathrm{~km}$ wide) zones is especially strong in the direction of shear.

Time-change in lateral shearing is shown in Figure 7. This velocity gradient becomes faster over time, which is curious in light of the grid-wide decrease in ice speed. Evidently, time-changes in ice velocity are not spatially uniform.

\section{Flowline turning $\left(\partial u_{t} / \partial l\right)$}

The along-flow gradient of across-flow velocity describes the change in across-flow motion as one proceeds downglacier. This flowline turning is generally to the glacier-left (counterclockwise) within the strain grid arca. The pattern of relatively more or relatively less glacier-leftward turning suggests that flow avoids two sites, $(x, y) \approx(-15,-8) \mathrm{km}$ in Figure $3 \mathrm{f}$ and $(x, y) \approx(3,-9) \mathrm{km}$ in Figure $4 \mathrm{f}$. Glacier-left of the sites, turning is relatively more leftward (more positive values of $\left.\partial u_{t} / \partial l\right)$. Glacier-right of the sites, turning is relatively more rightward (less positive $\partial u_{t} / \partial l$ ).

Time-change in flowline turning is shown in Figure 8. This velocity gradient also becomes faster over time but
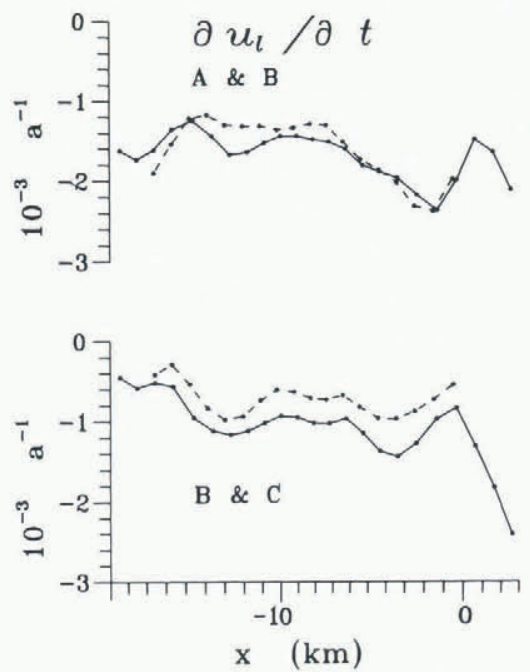

Fig. 7. Profiles of lateral shearing, $\partial u_{l} / \partial t$, in $10^{3} a^{-1}$. In general, lateral shearing is more rapid (more negative) in 1991-92 than in 1984-85. Exceptions are found along the A and $B$ lines profile. Up-glacier (more negative $x$ ), where a glacier-left-facing slope has become a glacier-right-facing slope, shearing has slowed. Down-glacier, where a surface valley has deepened, shearing has remained about the same.

with the opposite sign to the change in lateral shearing (Fig. 7). Together, these changes indicate little difference in the shear strain rate, $\left[\left(\partial u_{l} / \partial t\right)+\left(\partial u_{t} / \partial l\right)\right] / 2$, but a faster counterclockwise rotation of ice within the ice stream.
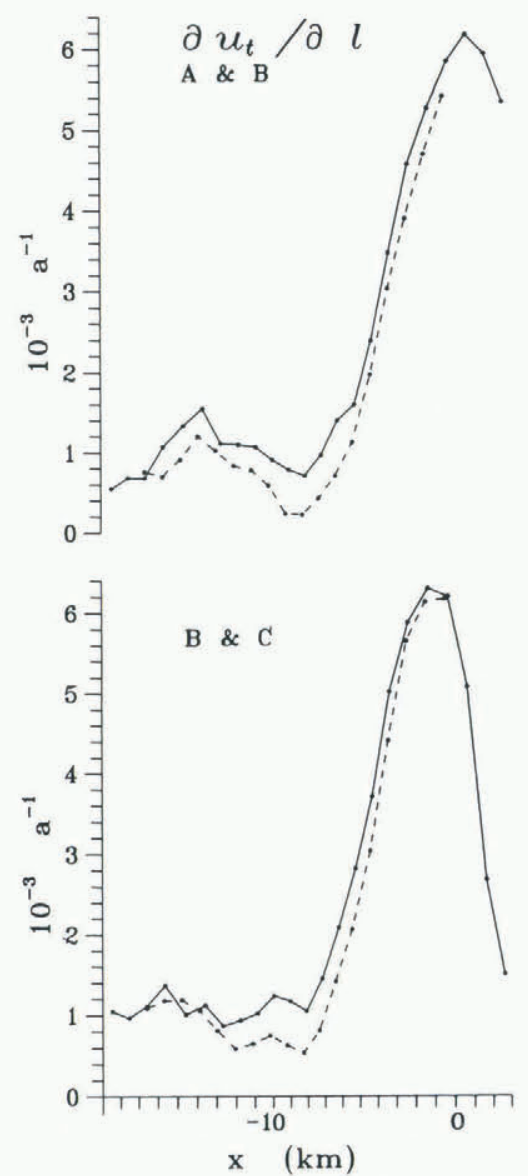

Fig. 8. Profiles of flowline turning, $\partial u_{t} / \partial l$, in $10^{-3} a^{-1}$. Glacier-leftward (southward) turning has increased for both profiles. 


\section{HORIZONTAL VARIATIONS IN ICE STRENGTH}

Spatial variations in strength in an ice stream may be due to variations in such properties as ice temperature or crystal orientation fabric. Shear margins located up-glacier could cause either kind of variation. Horizontal temperature gradients can result from strain heating within a margin. Simple calculations for the glacier-left shear margin of Ice Stream B (the Dragon) indicate a warming of 3-4 K that would persist for hundreds of years after the shear margin becomes inactive (Whillans and others, 1993). A second effect of shear is ice crystal alignment. Laboratory experiments and numerical modelling (Kamb, 1972; Van der Veen and Whillans, 1994) find that simple shear creates a fabric in which the $c$ axes of ice crystals are aligned perpendicular to the plane of dominant shear. Field observations made near nunataks of the Sør-Rondane Mountains, East Antarctica, differ from those results (Fujita and Mae, 1994). Ice samples collected there have $c$ axes that are aligned but oriented $\sim 45^{\circ}$ from the down-glacier direction and presumed dominant shear direction. Regardless of which type of alignment occurs, the alignment will persist until new strains develop a new fabric; the threshold strain for recrystallization is $40-$ $50 \%$ (Jacka and Maccagnan, 1984). Loss of crystal alignment by recrystallization would require $\sim 100$ years at the present study area, where strain rates are typically $2-3 \times$ $10^{-3} \mathrm{a}^{-1}$. Thus, long after a margin becomes inactive, elevated temperature or crystal alignment can persist within the ice.

Warmer ice is weak in all directions. It is subject to faster transverse compression and lateral shearing than adjacent, colder ice. No special longitudinal (along-flow) stretching is expected in a warm ice band, because colder (stiff) ice blocks on either side would act as stress guides, carrying the longitudinal normal stress. If the weak ice band is not vertical, transverse compression may cause stiffer ice on the hanging-wall side of the band to be displaced upward with respect to the block on the other side of the band.

A band of ice with an aligned crystal fabric is weak only to shear along the basal planes, perpendicular to $c$ axes. The band is easily deformed in that direction and is strong in others. For example, if $c$ axes are aligned across flow (basal planes parallel to flow), the band is weak to lateral shearing but strong to transverse compression. If the $c$ axes are not quite horizontal, transverse compression may result in relative vertical displacement of adjacent blocks.

Two bands of special deformation are identified in the study area (shaded in Figures 3 and 4). Transverse compression is especially fast (Figs $3 \mathrm{~d}$ and $4 \mathrm{~d}$ ) and the gradient in lateral shearing is very small across the up-glacier and down-glacier surface valleys (Figs 3 e and 4e). That combination implies ice that is weak in the transverse (acrossglacier) direction, while it is strong to shear (Fig. 9). The interpretation may be that the bands mark ice with a crystal fabric in which $c$ axes are diagonal to the flow direction, similar to the situation found near the Sor-Rondane Mountains (Fujita and Mae, 1994).

Changes in ice-stream topography over time indicate that the bands of aligned-crystal ice must be inclined. Hills will grow both vertically and laterally as displacement proceeds along an inclined band. In the present study area, the glacier-left side of each valley is moving relatively downward while ice on the glacier-right side is moving relatively upward. It appears that ice to the glacier-right of the bands

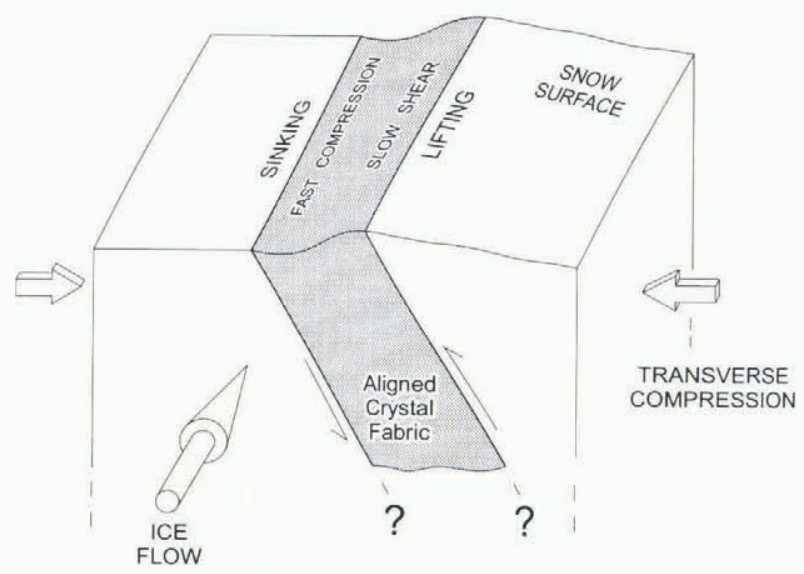

Fig. 9. Cartoon of a band of aligned-crystal ice. The analysis indicates crystals are aligned such that the band is weak to transverse compression and strong to lateral shear. Transverse compression causes the upper block to move upward (up-incline) relative to the lower block.

is being "pushed" up and to the left, over the aligned-crystal ice bands. This is similar to displacement of lithospheric blocks along a reverse fault, although in the ice stream there may be no discrete fault discontinuity. The direction of displacement implies that the bands dip toward the center of the glacier. Strain-rate changes between 1984-85 and 199192 are compatible with this interpretation. In both locations, the rates of transverse compression have decreased where stronger overriding ice supplanted an aligned-crystal band (Fig. 6). At the upstream site, lateral shearing has decreased slightly (Fig. 7) where the boundary between aligned-crystal and stiff ice has been replaced by a stiff ice hill.

The surface expression of an aligned-crystal band should change with time and down-glacier motion. The portion of the band exposed at the surface should narrow due to progressive overriding as adjacent ice is pushed up-dip. Consistent with this prediction, both the upstream and downstream surface valleys, which overlic the bands, narrow downstream, as do the regions of rapid transverse compression and slow lateral shearing. The proposed bands of aligned crystals seem to be overridden by adjacent ice.

\section{DEEP STRAIN RATES}

Deep strain rates can be inferred by considering volume continuity. This approach is practicable because the GPS surveying techniques used in this study yield precise vertical velocities. The principle of the calculation is that in order to conserve volume, transverse compression, for example, must be balanced by longitudinal and vertical extension. In general, these quantities, measured at the surface, do not balance one another. The imbalance is a measure of how much deep strain rates differ from measured surface strain rates. A method is developed in Appendix 2 to compute ice motion at depth using measured surface strain rates, vertical velocity, slope, and ice thickness. The resulting "deep divergence difference", $\Delta \dot{\epsilon}_{\mathrm{d}}$, is the additional deep strain rate required by continuity.

The deep divergence difference so calculated is shown in Figure 10. It is limited to the portion of the strain grid for which precise ice-thickness data are available (from Novick 


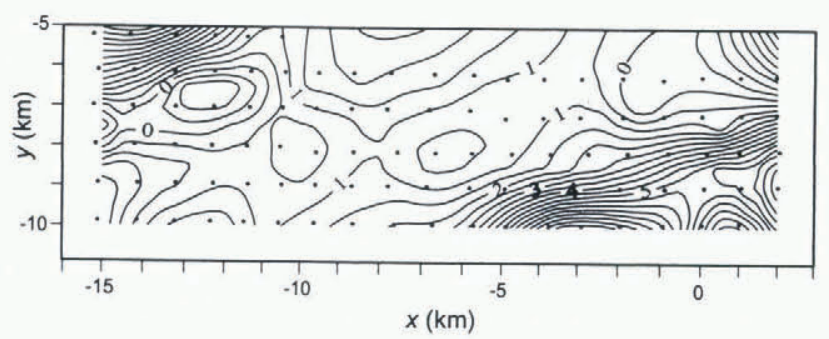

Fig. 10. Deep divergence difference, computed as discussed in Appendix 2. Isoline interval is $0.5 \times 10^{-3} a^{-1}$. Sites of large divergence (large positive values) are beneath the hypothetical aligned-crystal ice bands.

and others, 1994). Variations in transverse compression dominate the calculation. This is deduced from the similarity between Figures 3d and $4 \mathrm{~d}$ and Figure 10. Large positive values of deep divergence difference around $(x, y)=(-1$, $-9) \mathrm{km}$ and $(x, y)=(-15,-5.5) \mathrm{km}$ indicate sites of deep spreading. The negative anomaly at $(x, y)=(-13,-6.5) \mathrm{km}$ in Figure 10 suggests a destination for ice moving away from the positive anomaly to its glacier-left. That is, beneath the zones of rapid surface compression there is deep spreading.

The pattern of deep divergence difference is most readily interpreted in terms of lateral volume transfer. Relatively large spreading is occurring beneath both of the proposed aligned-crystal ice bands. To the glacier-right of the upstream aligned-crystal band, which is a site of anomalous upward motion at the surface, the calculated deep divergence difference is negative, indicating deep convergence. This site of negative divergence is the likely destination for ice moving away from the positive divergence beneath the band. This action supplies volume to the upward displacement of the adjacent ice block. The pattern is possibly the same for the downstream band, but that band is too close to the edge of the grid to determine the destination of deep ice. Deep ice seems to be moving from beneath the special bands to beneath uplifting ice.

\section{DISCUSSION}

The proposed model of aligned crystal bands explains most of the relationships among strain rates, vertical velocities, and ice-surface topography and changes over time. The bands suggested in Ice Stream B are weak in the across-flow direction and strong to lateral shear. They are possibly inclined toward the center of the ice stream, leading to along-incline displacement of ice and the creation of hills and valleys in the surface topography. The bands may have originated with the coalescence of up-glacier tributaries. Bands with aligned-crystal fabrics acquired in tributary shear margins would now be incorporated into the main body of the ice stream. A strain history like that at Sor-Rondane would account for the present crystal orientation: the bands are soft to transverse compression because crystals have $c$ axes oriented about $45^{\circ}$ to the transverse direction.

The importance of aligned-crystal bands to ice flow, and ice-flow models, depends on scale. In this study, bands of aligned ice crystals appear to dominate local variations in strain rate and surface slope (over several-kilometer distances). Analyses of the budget of forces on a horizontal scale similar to the ice thickness require that these bands be identified and accounted. Whillans and Van der Veen (1993b) did not do that in their Ice Stream B force-budget calculation but assumed, as has been usual, that ice strength varies only with stress and temperature, which is taken to vary only with depth. Neglect of the possibility of spatial variations in icecrystal alignment may account for the unusual values of basal drag, including negative values, they computed.

On the broad scale, bands of aligned ice crystals also affect assessment of the budget of forces. The shearing rate is at least two times slower and transverse compression is at least two times faster in the bands than in the surrounding ice (Figs 3 and 4). A reasonable guess for the fraction of special-strength ice is $10 \%$ (the fraction of the strain grid that overlies such ice). The gross-scale shearing rate is thus about $5 \%$ smaller $10 \%$ of two times larger strain rates) than if the aligned-crystal bands were absent. This error is small compared with other uncertainties in the use of a constitutive relation for ice. Thus, the bands do not dominate the broad-scale mechanics, so the usual approaches taken in modeling studies are not affected.

There is some similarity between the bands discovered here and the variable-strength banding proposed elsewhere for deep ice (Hooke and Hanson, 1986; Cunningham and Waddington, 1990). Though the banding in those examples is thought to be in near-horizontal layers and at a much finer scale than the bands identified in Ice Stream B, the effect is similar. Deformation is concent rated in weaker zones, while boudins of stiffer ice survive with much less strain. Some of the topographic highs in the ice stream, like the up-glacier hill (Fig. 3) or the hill near the UpB camp (Fig. 4), may be large boudins that have formed and continue to be deformed by the processes suggested here.

\section{ACKNOWLEDGEMENTS}

This work was supported by U.S. National Science Foundation grant DPP-9020760. C. L. Hulbe was also supported by the Graduate Fellowships for Global Change program administered by the Oak Ridge Institute for Science Education of the U.S. Department of Energy. M. Schenewerk, of the National Geodetic Survey, helped with absolute GPS positioning. The manuscript was much improved by candid reviews and discussions with J. Bolzan, D. MacAyeal and K. van der Veen, and by the comments of G. H. Gudmundsson and an anonymous reviewer. This is Byrd Polar Research Center contribution No. C-1038.

\section{REFERENCES}

Alley, R. B., D. D. Blankenship, C. R. Bentley and S. T. Rooney. 1986. Deformation of till beneath Ice Stream B, West Antarctica. Nature, 322 (6074), $57-59$.

Bindschadler, R. A., S. N. Stephenson, D. R. MacAyeal and S. Shabtaie. 1987. Ice dynamics at the mouth of Ice Stream B, Antarctica. 7. Geophys. Res., 92 (B9), 88858894.

Cunningham, J. and E. D. Waddington. 1990. Boudinage: a source of stratigraphic disturbance in glacial ice in central Greenland. 7. Glaciol., 36 (124), $269-272$.

Fujita, S. and S. Mae. 1994. Strain in the ice sheet deduced from the crystalorientation fabrics from bare icefields adjacent to the Sør-Rondane Mountains, Dronning Maud Land, East Antarctica. J. Glaciol., 40 (134), 135139.

Hooke, R. LeB. and B. Hanson. 1986. Borehole deformation experiments, Barnes Ice Cap, Canada. Cold Reg. Sci. Technol., 12 (3), 261-276.

Hooke, R. LeB., P. Calla, P. Holmlund, M. Nilsson and A. Stroeven. 1989. A 3 year record of seasonal variations in surface velocity, Storglaciären, Sweden. J. Glaciol., 35 (120), 235-247.

Hulbe, C. L. 1994. Flow of Ice Stream B, West Antarctica, and a method for determining ice thickness change at remote locations using differential GPS. M.Sc. thesis, Ohio State University. 
Hulbe, C. L. and I. M. Whillans. 1993. Stop-and-go GPS in Antarctica. Surv. Land Inf. Syst., $53(3), 150-158$.

Hulbe, C. L. and I. M. Whillans. 1994. Evaluation of strain rates on Ice Stream B, Antarctica, obtained using GPS phase measurements. Ann. Glaciol., 20, $254-262$.

Hutter, K. 1983. Theoretical glaciology; material science of ice and the mechanics of glaciers and ice sheets. Dordrecht; etc., D. Reidel Publishing Co.; Tokyo, Terra Scientific Publishing Co.

Jacka, T. H. and M. Maccagnan. 1984. Ice crystallographic and strain rate changes with strain in compression and extension. Cold Reg. Sci. Technol., 8(3), $269-286$.

Kamb, B. 1972. Experimental recrystallization of ice under stress. In Heard, H. C., I.Y. Borg, N. L. Carter and C. B. Raleigh, eds. Flow and fracture of rocks. Washington, DC, American Geophysical Union, 2ll-241. (Geophysical Monograph 16.

Lliboutry, L. 1995. Correspondence. Why calculated basal drags of ice streams can be fallacious. F. Glaciol., 41 (137), 204- 205.

McDonald, J. and I. M. Whillans. 1992. Search for temporal changes in the velocity of Ice Stream B, West Antarctica. 7. Glaciol., 38(128), 157-161.

Novick, A. N., C. R. Bentley and N. Lord. 1994. Ice thickness, bed topography and basal-reflection strengths from radar sounding, Upstream B, West Antarctica. Ann. Glaciol., 20, 148-152.

Paterson, W. S. B. 1981. The physics of glaciers. Second edition. Oxford, etc., Pergamon Press.

Raymond, C. F. 1971. Flow in a transverse section of Athabasca Glacier, Alberta, Canada. 7. Glaciol., 10 (58), 55-84.

Retzlaff, R., N. Lord and C. R. Bentley. 1993. Airborne-radar studies: Ice Streams A, B and C, West Antarctica. J. Glaciol., 39 (133), 495-506.

Van der Veen, C. J. and I. M. Whillans. 1989. Force budget: I. Theory and numerical methods. f. Glaciol., 35(119), 53-60.

Van der Veen, C. J. and I. M. Whillans, 1990. Flow laws for glacier ice: comparison of numerical predictions and field measurements. F. Glaciol., 36 (124), 324-339.

Van der Veen, C. J. and I. M. Whillans. 1994. Development of fabric in ice. Cold Reg. Sci. Technol., 22 (2), 171-195.

Vornberger, P. L. and I. M. Whillans. 1990. Crevasse deformation and examples from Ice Stream B, Antarctica. J. Glaciol., 36(122), 3-10.

Wells, D. 1987. Guide to GPS positioning. Fredericton, N.B., Canadian GPS Associates.

Whillans, I. M. and S. J. Johnsen. 1983. Longitudinal variations in glacial flow: theory and test using data from the Byrd Station strain network, Antarctica. 7. Glaciol., 29 (101), 7897.

Whillans, I. M. and C.J. van der Veen. 1993a. New and improved determinations of velocity of Ice Streams B and C, West Antarctica. 7. Glaciol., 39 (133), 483-490.

Whillans, I. M. and C. J. van der Veen. 1993b. Patterns of calculated basal drag on Ice Streams B and C, Antarctica. 7. Glaciol., 39 (133), 437-446.

Whillans, I. M. and K. van der Veen. 1995. Correspondence. Reply to Lliboutry's letter "Why calculated basal drags of ice streams can be fallacious". J. Glaciol., 41 (137), $205-206$.

Whillans, I. M., J. Bolzan and S. Shabtaie. 1987. Velocity of Ice Streams B and C, Antarctica. J. Geophys. Res., 92(B9), 8895-8902.

Whillans, I. M., M. Jackson and Y. -H. Tseng. 1993. Velocity pattern in a transect across Ice Stream B, Antarctica. J. Glaciol., 39 (133), 562-572.

\section{APPENDIX A}

\section{STRAIN GRID SURVEYS}

The small strain grid was installed and surveyed in November 1983 and resurveyed in late 1984 and again in late 1985. The expanded grid was surveyed in November and December of 1991 and of 1992. The 1980s surveys were made using electronic distance measuring instruments (EDMIs) and pressure altimeters (Whillans and Van der Veen, 1993b). The more recent work was done using phase-tracking GPS surveying (Hulbe and Whillans, 1993). Relative velocities between adjacent gridpoints from both EDMI and GPS surveys are repeatable to $0.01 \mathrm{~m} \mathrm{a}^{-1}$. The accuracy of relative heights measured by pressure altimetry is within $2 \mathrm{~m}$. Relative vertical positioning by GPS surveying is repeatable to $0.01 \mathrm{~m} / 1000 \mathrm{~m}$ (baseline lengths ranged from 1 to $5 \mathrm{~km}$ ).

Absolute velocities are determined using long-distance satellite tracking. Long-time TRANSIT satellite (Doppler) observations at station "330" $((x, y) \approx(-10,-9) \mathrm{km})$ and station " 01 " at the UpB camp site $((x, y) \approx(3,-7) \mathrm{km})$ have been made on many occasions (Whillans and Van der Veen, 1993a). TRANSIT-determined positions of the stations in 1984 and 1985 are used to calculate their 1984-85 velocities. Stretching between stations 01 and 330, calculated from their absolute velocities, agrees with stretching determined from the strain-grid (relative velocity) surveys. The velocity of station 330 is used as a reference from which absolute velocities of other gridpoints are determined. Error of the 1984-85 absolute velocities is about $1.0 \mathrm{~m} \mathrm{a}^{-1}(1 \sigma)$. The 1991-92 velocity of a long-duration GPS tracking station, "Z20" (294 $\mathrm{m}$ from station 01), is determined relative to a GPS receiver on rock at McMurdo Station, on Ross Island. The solutions are L1/L2 ("ion-free") double differences, with precise orbits (personal communication from M. Schenewerk, National Geodetic Survey). Z20 is the reference from which other gridpoint velocities are calculated. The error in the 1991-92 absolute velocities is within $0.4 \mathrm{~m} \mathrm{a}^{-1}$ $(1 \sigma)$.

Baselines measured by satellite tracking may be misoriented due to uncertainty in satellite orbits. Misorientation of the grid in one or more of the surveys would result in an artificial rotation of the grid in either the 1984-85 or 199192 calculations or the comparison between the two, and produce misleading results, most especially flowline turning $\left(\partial u_{t} / \partial l\right)$. The absolute positions of stations 330 and 01 , located at opposite ends of the grid, are known to within $1 \mathrm{~m}(1 \sigma)$ (McDonald and Whillans, 1992; Whillans and Van der Veen, 1993a). Those points are used to constrain the 1980 s grid positioning. Thus the maximum possible rotation is very small, $\pm 1 \mathrm{~m}$ at either end of the grid. Errors reported in satellite navigation messages are used to determine misorientation error for the 1990s GPS surveys. Satellite-range accuracies vary from 2.8 to $32 \mathrm{~m}$. A rule of thumb (Wells, 1987) is:

$$
\frac{|\mathrm{d} b|}{|b|}=\frac{|\mathrm{d} r|}{\rho}
$$

where $|\mathrm{d} b|$ represents the magnitude of the length error due to misorientation, $b$ represents the observed baseline length, $|\mathrm{d} r|$ represents the satellite-range error, and $\rho$ represents the range to the satellite $(20000 \mathrm{~km}$ for GPS $)$. For every baseline solution, there will be an error $|\mathrm{d} b|$ for each GPS satellite in view. Because the GPS satellites are distributed around the sky, range errors will be in different directions and tend to cancel. The rule of thumb provides an estimate of the maximum possible orientation error by supposing that the orbits of all satellites have errors that point in the same direction. Considering one satellite, a $5 \mathrm{~km}$ baseline and a satellite position error of $32 \mathrm{~m}$, an upper limit for $|\mathrm{d} b|$ is $0.008 \mathrm{~m}$. That value is on the order of the GPS vector repeatabilities. The rotation error is less than $0.002 \mathrm{~m} / 1000 \mathrm{~m}$. The net effect for the comparison between 1984-85 and 1991-92 observations is a possible horizontal misorientation of $\pm 1 \mathrm{~m}$.

A limited number of EDMI baseline measurements was made for comparison with GPS observations. EDMI distances (about $1 \mathrm{~km}$ ) in November 1991 are shorter than those measured with GPS, by $2 \times 10^{-5} \mathrm{~m}$. We have been unable to identify the source of the discrepancy. It could lie with either measurement technique or human error in the EDMI work. Similar tests in December 1993 find no consistent difference between EDMI- and GPS-measured baselines. If the discrepancy noted in 1991 between GPS and EDMI 
baselines applies to both the 1991 and 1992 surveys, it does not affect gradient calculations made using only GPS measurements. If, however, the discrepancy is only with the 1991 distances, there would be a $1 \%$ artificial difference between GPS- and EDMI-derived strain rates (based on a typical strain rate of $\left.2 \times 10^{-3} \mathrm{a}^{-1}\right)$. That difference is small compared to the strain-rate changes (up to $28 \%$ ) discussed here.

\section{APPENDIX B}

\section{HORIZONTAL DIVERGENCE AT DEPTH}

An objective of measuring surface strain rates is to estimate strain rates and stresses deep in the ice stream (e.g. the force budget method of Van der Veen and Whillans, 1989). Typically, such calculations assume that the ice is isotropic and the rate factor (ice strength) varies only with depth. Neither assumption seems appropriate for the UpB data. Here, a more simple kinematic approach is taken in which deep strain rates are inferred by requiring ice-volume conservation.

The calculation is based on comparison of measured surface strain rates with strain rates needed to achieve fullthickness volume balance. Full-thickness vertical strain rates are estimated from along-flow gradients in ice thickness, surface velocities and slopes, basal melting and surface accumulation. Any imbalance between horizontal strain rates measured at the surface and estimated vertical strain rates is attributed to strain rates at depth.

Incompressibility of ice is expressed in terms of normal strain rates, $\dot{\epsilon}$, in a Cartesian coordinate system $(x, y, z)$ :

$$
\dot{\epsilon}_{x x}+\dot{\epsilon}_{y y}+\dot{\epsilon}_{z z}=0 .
$$

The $x$ and $y$ axes are horizontal, and the vertical, $z$, axis is positive upward. Volume balance of a column of ice is obtained by integrating Equation (A2) from the base, $z=b$, to the surface, $z=h$, of the column:

$$
\int_{b}^{h}\left(\dot{\epsilon}_{x x}+\dot{\epsilon}_{y y}+\dot{\epsilon}_{z z}\right) \mathrm{d} z=0 .
$$

This is arranged into horizontal and vertical terms:

$$
\int_{b}^{h}\left(\dot{\epsilon}_{x x}+\dot{\epsilon}_{y y}\right) \mathrm{d} z=-\int_{b}^{h} \dot{\epsilon}_{z z} \mathrm{~d} z,
$$

which are considered separately.

Vertical strain rate, $\dot{\epsilon}_{z z}$, is readily integrated:

$$
\int_{b}^{h} \dot{\epsilon}_{z z} \mathrm{~d} z=u_{z}(h)-u_{z}(b),
$$

being the difference between vertical velocity at the surface, $u_{z}(h)$, and the base, $u_{z}(b)$, of the ice stream. Computation of vertical velocity is considered later.

Integration of the horizontal strain rates necessitates a means to account for deep divergence, the object of this exercise. Horizontal divergence, $\left(\dot{\epsilon}_{x x}+\dot{\epsilon}_{y y}\right)$, is considered to be the sum of the divergence measured at the surface, $\dot{\epsilon}_{\mathrm{s}}$, and a deep divergence anomaly, $\Delta \dot{\epsilon}_{\mathrm{d}}(x, y) \mathcal{F}(z)$. Horizontal variations in the anomaly $\Delta \dot{\epsilon}_{\mathrm{d}}(x, y)$ are separated from vertical variations, $\mathcal{F}(z)$ :

$$
\left(\dot{\epsilon}_{x x}+\dot{\epsilon}_{y y}\right)=\dot{\epsilon}_{\mathrm{s}}(x, y)+\Delta \dot{\epsilon}_{\mathrm{d}}(x, y) \mathcal{F}(z) .
$$

The deep strain rate difference, $\Delta \dot{\epsilon}_{\mathrm{d}}$, is the amount by which deep divergence must differ from surface divergence to achieve volume conservation. The shape function is equal to zero at the surface, but selection of its value at depth is somewhat arbitrary. The separation of the deep divergence difference into horizontal $(x, y)$ and vertical $(z)$ variations simplifies the interpretation of the anomaly pattern. As shown below, $\mathcal{F}$ has mainly a scaling effect.

Applying Equations (A5) and (A6) to Equation (A4) yields

$$
\dot{\epsilon}_{\mathrm{s}} H+\dot{\epsilon}_{\mathrm{d}} \int_{b}^{h} \mathcal{F}(z) d z=u_{z}(b)-u_{z}(h)
$$

at any horizontal location $(x, y)$. Ice thickness is $H=h-b$. Equation (A7) is solved to find the deep divergence difference:

$$
\Delta \dot{\epsilon}_{\mathrm{d}}=\frac{-\dot{\epsilon}_{\mathrm{s}} H+u_{z}(h)-u_{z}(b)}{\int_{b}^{h} \mathcal{F}(z) \mathrm{d} z} .
$$

This is our object. Note that the functional form of $\mathcal{F}(z)$ affects the scale but not the pattern of horizontal variation of $\Delta \dot{\epsilon}_{\mathrm{d}}$.

Vertical velocities, $u_{z}(h)$ and $u_{z}(b)$, are linked to slopes and accumulation or melt rates. At the upper surface, vertical velocity is determined by the rate of new snow accumulation, $\dot{a}$; the rate of change of surface elevation the "vertical velocity anomaly" discussed in the section "Flow Characteristics"), $h$; and flow up or down the surface slope, the product of horizontal velocity and slope, $u_{x}(\partial h / \partial x)$ and $u_{y}(\partial h / \partial y)$. The combined effect is:

$$
u_{z}(h)=-\dot{a}+h+u_{x}(h) \frac{\partial h}{\partial x}+u_{y}(h) \frac{\partial h}{\partial y} .
$$

Vertical velocity at the base is described by a similar relation, in which the basal freeze rate, $\dot{f}$ (negative for melt), changes in basal elevation, $b$, and flow along the basal slope, $u_{x}(\partial b / \partial x)$ and $u_{y}(\partial b / \partial y)$, are considered. The combined effect is:

$$
u_{z}(b)=\dot{f}-\dot{b}+u_{x}(b) \frac{\partial b}{\partial x}+u_{y}(b) \frac{\partial b}{\partial y} .
$$

By any model for the ice stream, vertical shear stresses are very small, so, to a good approximation, $u_{x}(h) \approx u_{x}(b)$, and $u_{y}(h) \approx u_{y}(b)$, and the surface and base horizontal velocity terms may be combined. Gathering the $x$ components:

$$
\begin{aligned}
{\left[u_{x}(h) \frac{\partial h}{\partial x}-u_{x}(b) \frac{\partial b}{\partial x}\right] \approx u_{x}(h) } & \left(\frac{\partial h}{\partial x}-\frac{\partial b}{\partial x}\right) \\
& =u_{x}(h)\left(\frac{\partial H}{\partial x}\right) .
\end{aligned}
$$

Similar equations may be written for the $y$ components. Applying these, the difference between surface and basal velocity is:

$$
u_{z}(h)-u_{z}(b) \approx-\dot{a}+\dot{h}-\dot{f}+\dot{b}+u_{x}(h) \frac{\partial H}{\partial x}+u_{y}(h) \frac{\partial H}{\partial y},
$$

which is used in Equation (A8) to compute deep divergence difference.

Measurements required to calculate deep divergence difference are available for about half the UpB strain grid. Horizontal velocities, strain rates and the rate of change of surface clevation (the vertical velocity anomaly) are from the strain grid surveys discussed in this study. Ice-penetrating radar observations (Novick and others, 1994) provide ice thicknesses (these data limit the region for the calculation). Accumulation rates are calculated from time-changes in the exposed height of strain-grid marker poles (unpublished 
data). Basal freeze/melt rates are unknown but are probably less than $0.02 \mathrm{~m} \mathrm{a}^{-1}$ (Alley, and others, 1986) and are neglected. There are no data available to determine the rate of change in basal shape, $\dot{b}$. For simplicity, we assume the shape of the bed is not changing.

As noted above, the selection of $\mathcal{F}(z)$, a function that describes the depth variation of the horizontal divergence, is arbitrary. It is sometimes assumed that the ice stream consists of an upper cold layer and a lower, warmer, layer (cf. Lliboutry, 1995; Whillans and Van der Veen, 1995). One might expect no significant flow variation in the cold "lid" of the ice stream; that is, $\mathcal{F}(h>z>h-c H)=0$, where $c$ represents the fraction of the ice thickness that is cold. The nature of $\mathcal{F}(z)$ in the deep, warm ice is unknown. For sim- plicity, we select a depth variation function such that $\int_{b}^{h} \mathcal{F}(z) \mathrm{d} z=1$. A different value would scale the results in Figure 10 accordingly.

Measurement errors affect the confidence in calculated deep divergence difference, $\dot{\epsilon}_{\mathrm{d}}$. Relative velocities and strain rates are accurate within $0.014 \mathrm{~m} \mathrm{a}^{-1}$ and $0.03 \times 10^{-3} \mathrm{a}^{-1}$, respectively. Uncertainties in ice thickness and relative thickness change are conservatively estimated to be $10 \mathrm{~m}$ and $0.5 \mathrm{~m} / 1000 \mathrm{~m}$, respectively. Exposed pole length measurement errors combine to produce an accumulation rate error of about $0.028 \mathrm{~m} \mathrm{a}^{-1}$. Using those values, a typical error in $\Delta \dot{\epsilon}_{\mathrm{d}}$ is $0.2 \times 10^{-3} \mathrm{a}^{-1}$, or about $10 \%$ of the computed divergence. 